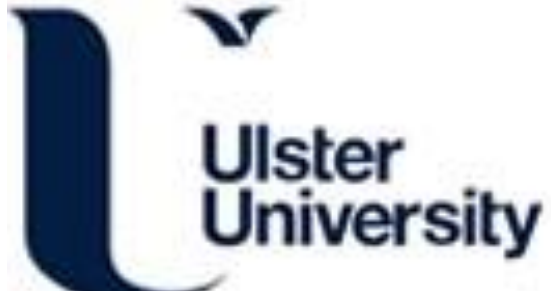

\section{Application of Liquid Chromatography-Tandem Mass Spectrometry To Determine Urinary Concentrations of Five Commonly Used Low-Calorie Sweeteners: A Novel Biomarker Approach for Assessing Recent Intakes?}

\begin{abstract}
Logue, C., Dowey, L. R., Strain, JJ., Verhagen, H., Mcclean, S., \& Gallagher, A. (2017). Application of Liquid Chromatography-Tandem Mass Spectrometry To Determine Urinary Concentrations of Five Commonly Used Low-Calorie Sweeteners: A Novel Biomarker Approach for Assessing Recent Intakes? Journal of Agricultural and Food Chemistry, 65(22), 4516-4525. https://doi.org/10.1021/acs.jafc.7b00404
\end{abstract}

Link to publication record in Ulster University Research Portal

Published in:

Journal of Agricultural and Food Chemistry

Publication Status:

Published (in print/issue): 07/06/2017

DOI:

10.1021/acs.jafc.7b00404

Document Version

Author Accepted version

\section{General rights}

Copyright for the publications made accessible via Ulster University's Research Portal is retained by the author(s) and / or other copyright owners and it is a condition of accessing these publications that users recognise and abide by the legal requirements associated with these rights.

\section{Take down policy}

The Research Portal is Ulster University's institutional repository that provides access to Ulster's research outputs. Every effort has been made to ensure that content in the Research Portal does not infringe any person's rights, or applicable UK laws. If you discover content in the Research Portal that you believe breaches copyright or violates any law, please contact pure-support@ulster.ac.uk. 
1 Application of liquid chromatography-tandem mass spectrometry to determine urinary

2 concentrations of five commonly used low-calorie sweeteners: a novel biomarker approach

3 for assessing recent intakes?

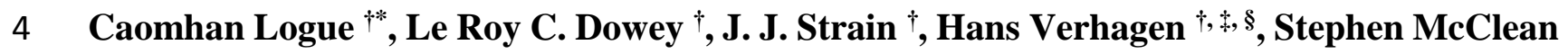

$5 \quad$ ', and Alison M. Gallagher ${ }^{\dagger}$

6 Nutrition Innovation Centre for Food and Health (NICHE), Ulster University, Coleraine,

$7 \quad$ Northern Ireland BT52 1SA

8 National Institute for Public Health and the Environment (RIVM), P.O. Box 1, 3720 BA,

9 Bilthoven, The Netherlands (until 1 Nov 2015)

$10 \S$ European Food Safety Authority (EFSA), Parma, Italy (from 1 Nov 2015)

11 *Corresponding Author. Telephone: +44 (0)2870 124451. Email: c.logue@ulster.ac.uk. 
12 Abstract

13 Although the use of low-calorie sweeteners (LCSs) is widespread, methods of assessing 14 consumption within free-living populations have inherent limitations. Five commonly consumed

15 LCSs, namely acesulfame-K, saccharin, sucralose, cyclamate and steviol glycosides are excreted

16 via the urine and therefore a urinary biomarker approach may provide more objective LCS intake

17 data. A LC-ESI-MS/MS method of simultaneously determining acesulfame-K, saccharin,

18 sucralose, cyclamate and the excretory metabolite of steviol glycosides, steviol glucuronide, in

19 human urine was developed and validated. Linearity was observed over a concentration range of

$20 \quad 10-1000 \mathrm{ng} / \mathrm{ml}$ with coefficients of determination ranging from 0.9969 to 0.9997 . Accuracy ranged

21 from 92 to $104 \%$ and intra-batch and inter-day precision were within acceptable limits with \% CV

22 below $8 \%$ for all compounds. A double-blind, randomized cross-over dose-response study was

23 conducted to assess the usefulness of urinary LCS excretions (from both fasting spot and a full 24-

24 hour urine collection) for investigating recent intakes. Both modes of sampling were useful for

25 distinguishing between the three short-term intakes of acesulfame-K, saccharin, cyclamates and 26 steviol glycosides $(\mathrm{p}<0.001)$ while for sucralose, urinary concentrations were useful for 27 distinguishing between low (0.1\% ADI) and high doses $(10 \%$ ADI) only $(\mathrm{p}<0.001)$. In summary, 28 this biomarker approach may be useful for assessing intakes of five commonly consumed LCSs.

29 Keywords: low-calorie sweeteners; intense sweeteners; biomarkers; urinary biomarkers; 30 exposure; food additives; human urine. 


\section{Introduction}

32 The prevalence of obesity, a major risk factor for the development of chronic conditions such as

33 cardiovascular disease, type 2 diabetes mellitus and hypertension, ${ }^{1}$ has increased significantly over

34 recent decades. ${ }^{2-4}$ Although its cause at the population level is multi-factorial, ${ }^{1}$ central to its

35 occurrence at the individual level are lifestyles characterized by sedentary behaviors and unhealthy

36 dietary practices. One dietary practice that has been implicated in contributing to overweight and

37 obesity, as well as other adverse health outcomes, is the over-consumption of free sugars,

38 particularly from sugar-sweetened beverages. ${ }^{5,6}$ As such, recently published guidelines

39 recommend that intakes of free sugars should not exceed $5 \%{ }^{6}$ or $10 \%$ of total energy intake. Given

40 that current free sugar intakes within the population largely exceed these recommendations, ${ }^{6}$

41 strategies that support a reduction in intake, while maintaining diet palatability, include the

42 substitution of free sugars with low-calorie sweeteners (LCSs).

43 LCSs are a chemically diverse group of intensely sweet, low energy, food additives that are non-

44 cariogenic $^{7}$ and used in a wide range of dietary and non-dietary products to provide a desired sweet

45 taste without increasing energy density or inducing adverse oral health outcomes. Intuitively, LCSs

46 should be expected to offer health benefits when used in place of free sugars; indeed, a recent

47 meta-analysis of RCTs (sustained over 4 weeks to 40 months) indicated that LCS consumption

48 versus sugar led to reductions in body weight. ${ }^{8}$ Despite such health benefits, debate around their

49 long-term efficacy continues, particularly in relation to weight management, ${ }^{9}$ type 2 diabetes ${ }^{10,11}$

50 and other metabolic effects. ${ }^{12}$ A number of mechanisms by which LCSs may adversely impact on

51 health have been discussed and while a number of these putative mechanisms have been supported

52 by some animal data, none have yet been demonstrated in humans. ${ }^{13}$ Observational data, in

53 particular, have been conflicting in relation to the health effects of LCSs, as highlighted in a recent 
54 review of the evidence by the French Agency for Food, Environmental and Occupational Health 55 and Safety (ANSES); ${ }^{14}$ however a major limitation of most cohort studies is that only low-calorie 56 sweetened beverage (LCSB) consumption is considered when investigating associations between

57 LCSs and health. LCSs are ubiquitous in today's society and LCSBs are only one of many sources

58 of LCSs in the diet; indeed, some LCSs have recently been identified as potential environmental

59 contaminants and detected in drinking-water sources ${ }^{15}$ so exposure to some LCSs may actually

60 occur inadvertently in certain populations. Furthermore, intakes of individual LCSs are very rarely

61 estimated in cohort studies, ${ }^{14}$ impairing the ability to properly explore relationships between these

62 chemically diverse food additives and health. This is further compounded by the fact that blends

63 of LCSs are now often used within the same product. With these factors in mind, conclusions

64 drawn from current observational data are likely to be tenuous and therefore, an alternative

65 approach which provides more objective and specific LCS intake data would be highly desirable

66 in order to enhance research in the area of LCSs and human health.

67 A nutritional biomarker approach involving the measurement of components of the diet, or their

68 metabolites, as indicators of intake may offer an opportunity to more objectively and specifically

69 assess intakes of LCSs and therefore address a number of fundamental limitations with some

70 current research approaches into the health impacts of LCS use. Such an approach has previously

71 been utilized for investigating intakes of other dietary components such as salt, protein and

72 wholegrains. ${ }^{16,17}$ A number of LCSs, once absorbed into the body, are excreted via the urine

73 following little or no metabolism. ${ }^{18}$ Urinary excretions of acesulfame- $\mathrm{K}$ and saccharin were

74 previously investigated as potential biomarkers of intakes and were found to be useful. ${ }^{19}$ Of the

75 other commonly used LCSs, sucralose and cyclamate may also be suitable for a urinary biomarker

76 approach as the absorbed proportion is excreted largely unchanged via the urine. ${ }^{18,20}$ Steviol 
77 glycosides, in contrast, undergo bacterial hydrolysis to steviol in the large intestine and, following 78 absorption, are excreted in the urine as steviol glucuronide, ${ }^{21}$ as such, this metabolite may prove

79 to be a useful biomarker of intake. To determine the feasibility of such a biomarker approach, it is

80 first necessary to develop a suitable and reliable analytical method for measuring the compounds

81 of interest. ${ }^{22,23}$ One of the most commonly reported techniques for simultaneously analyzing LCSs

82 in foods, beverages, and in water samples, is liquid chromatography with mass spectrometry using 83 electrospray ionization (LC-ESI-MS/MS) ${ }^{15,24-27}$ Validation of the biomarker should also be

84 conducted to characterize the relationship between the candidate marker and the dietary 85 component of interest. ${ }^{28}$

86 The present work consisted of two studies with distinct aims: firstly, to develop and validate a LC-

87 ESI-MS/MS method of simultaneously determining acesulfame-K, saccharin, sucralose and 88 cyclamate and steviol glucuronide in human urine and secondly, to assess whether urinary 89 excretions of these compounds are useful for investigating short-term intakes of the respective 90 LCS. It was hypothesized that urinary excretions of the compounds of interest would be useful for 91 distinguishing between three levels of intake relevant to the free-living population.

\section{Materials and Methods}

\section{Method development and dose-response studies}

\section{Reagents and reference materials}

95 High performance liquid chromatography (HPLC) grade water and HPLC grade methanol were 96 purchased from Fisher Chemicals (Loughborough, UK). Ammonium carbonate, along with 97 acesulfame-K, sodium saccharin, sodium cyclamate and sucralose, were purchased from Sigma98 Aldrich (St. Louis, MO, USA). Steviol glucuronide (96.4\% purity by HPLC) was kindly supplied 
99 by The Coca-Cola Company (Atlanta, US). Acesulfame-d4 potassium salt (Ace-d4), sucralose-d6 100 (Suc-d6) and saccharin-d4 (Sac-d4) were purchased from Toronto Research Chemicals Inc. 101 (Toronto, Canada) while sodium cyclamate-d11 (Cyc-d11) and warfarin sodium were purchased 102 from QMX Laboratories (Thaxted, UK) and Sigma-Aldrich (St. Louis, MO, USA) respectively. 103 All reference materials were of analytical standard.

104 Individual stock solutions of $1 \mathrm{mg} / \mathrm{ml}$ were prepared in water/methanol (50:50) for acesulfame-K, 105 sodium saccharin, sodium cyclamate, sucralose and steviol glucuronide and from these, a working 106 solution containing all five compounds at concentrations of $0.1 \mathrm{mg} / \mathrm{ml}$ was prepared in 107 water/methanol (50:50) and stored at $4{ }^{\circ} \mathrm{C}$. For the internal standards (IS), individual stock 108 solutions of $1 \mathrm{mg} / \mathrm{ml}$ were prepared in methanol for Ace-d4, Sac-d4 and Suc-d6. Warfarin sodium 109 and Cyc-d11 were dissolved in water/methanol (50:50) at concentrations of $80 \mu \mathrm{g} / \mathrm{ml}$ and $40 \mu \mathrm{g} / \mathrm{ml}$ 110 respectively. Prior to each batch, a working solution containing $5 \mu \mathrm{g} / \mathrm{ml}$ Ace-d4, Sac-d4, Suc-d6 111 and $4 \mu \mathrm{g} / \mathrm{ml}$ and $2 \mu \mathrm{g} / \mathrm{ml}$ warfarin sodium and Cyc-d11 respectively was prepared in mobile phase 112 A (MP-A) (see below for MP-A composition).

113 Boric acid, purchased from Sigma-Aldrich (St. Louis, MO, USA), was used as a preservative in 114 urine samples by adding $10 \mathrm{~g}$ to each 3 liter container. Completeness of 24-hour urine collections 115 was assessed using the paraminobenzoic acid (PABA) method. ${ }^{29}$ During each 24-hour urine 116 collection period, participants were asked to consume one tablet containing $80 \mathrm{mg}$ PABA at three 117 specified times (8am, 12pm and 6pm; $240 \mathrm{mg}$ in total) and a recovery of at least $187 \mathrm{mg}(78 \%$ of 118 the dose) signified a complete sample. ${ }^{30} \mathrm{PABA}$ tablets were purchased from the Medical Research 119 Council (Cambridge, UK). If participants forgot to take all three PABA tablets yet reported 120 collecting a complete 24-hour sample, the urine sample was also considered complete. 
122 Method development and validation was conducted on a HPLC-MS system consisting of a Thermo

123 Separation Products HPLC system (Waltham, US) interfaced with a QTrap 3200 hybrid

124 quadrupole-linear ion trap mass spectrometer (AB Sciex, Warrington, UK). Urine analysis in the 125 dose-response study was conducted on a HPLC-MS system consisting of a Shimadzu UHPLC 126 system (Milton-Keynes, UK) and an API 4000 triple quadrupole mass spectrometer (AB Sciex,

127 Warrington, UK) following method transfer and optimization of MS conditions.

\section{Method development and validation}

\section{Collection of LCS-free urine samples for method development}

130 Twelve apparently healthy volunteers (6 females; 6 males; age range, 21-51 years) were recruited

131 to provide blank urine samples for the purposes of method development and validation. Those

132 with diabetes, renal impairment, taking or planning to take sulfonamide antibiotics during the study

133 or with lactose intolerance were excluded from the study. Participants were asked to avoid foods

134 and beverages known to contain acesulfame-K, saccharin, cyclamate, sucralose and steviol 135 glycosides for a period of at least three days prior to collecting a 24-hour urine sample. To aid this, 136 verbal advice and literature were provided to each participant. From each sample, ten 1 ml aliquots 137 and two $30 \mathrm{ml}$ aliquots were retained and stored at $-80{ }^{0} \mathrm{C}$ for later use in method development.

138 Ethical approval was granted for this method development study by the Ulster University 139 Biomedical Sciences Research Ethics Filter Committee (Study No: FCBMS-13-058). 
141 All urine samples $(n=12)$ were screened for the presence of the compounds of interest and those

142 found with no or negligible concentrations $(n=6)$, were used for the purposes of method

143 development and validation. Calibration and quality control (QC) samples were prepared by

144 fortifying blank urine samples with known concentrations of the compounds of interest.

145 For the preparation of calibration standards, fortification solutions at concentrations of 1.0, 12.5, $14625.0,37.5,50.0,75.0$ and $100.0 \mu \mathrm{g} / \mathrm{ml}$ were prepared from the respective LCS working solution.

147 Fortification solutions were also prepared at concentrations of $12.5,55.0$ and $93.0 \mu \mathrm{g} / \mathrm{ml}$ and these 148 were used for the preparation of QC samples which were run during each batch. Fortification of 149 the blank urine samples resulted in a 10-fold dilution of these concentrations.

\section{Sample preparation}

151 A simple preparation procedure was used in which fortified urine samples underwent a further 10-

152 fold dilution and were filtered. Each sample was vortexed for a minimum of 10 seconds to ensure

153 homogenization and $100 \mu \mathrm{l}$ was mixed with $20 \mu \mathrm{l}$ of IS working solution in a $1.5 \mathrm{ml}$ tube and made

154 up to $1 \mathrm{ml}$ using MP-A (see below for composition of MP-A). The mixture was again vortexed for 155 a minimum of 10 seconds and filtered using a $0.22 \mu \mathrm{m}$ mixed cellulose ester filter membrane 156 (Merck KGaA, Darmstadt, Germany). From the filtrate, $100 \mu \mathrm{l}$ was retained for analysis.

\section{Liquid chromatography-tandem mass spectrometry conditions}

158 Separation was accomplished using a Poroshell 120 EC-C18 $(4.6$ x $50 \mathrm{~mm}), 2.7 \mu \mathrm{m}$ column 159 equipped with a Poroshell 120 UHPLC EC-C18 guard column (Agilent Technologies, Santa Clara, 160 US). HPLC conditions from an Agilent Technologies application note ${ }^{31}$ were adapted for the 161 purposes of this method. Flow rate was maintained at $0.6 \mathrm{ml} / \mathrm{min}$ throughout and a binary gradient

162 program was used. MP-A consisted of $2 \mathrm{mM}$ ammonium carbonate in water/methanol (95/5\%) 
163 ( $\mathrm{pH} 8.8$ ) and mobile phase B (MP-B) consisted of $2 \mathrm{mM}$ ammonium carbonate in methanol ( $\mathrm{pH}$

164 8.9). The gradient program was as follows: $0 \mathrm{~min}, 100 \% \mathrm{~A}, 7.0 \mathrm{~min}, 25 \% \mathrm{~A}, 9.0 \mathrm{~min}, 25 \% \mathrm{~A}, 9.1-$

$16515.0 \mathrm{~min}, 100 \%$ A. Sample injection volume was $20 \mu \mathrm{l}$ and the needle was flushed with $500 \mu \mathrm{l}$ of 166 a water/methanol (60/40\%) solution following each injection. Column temperature was 167 maintained at $30{ }^{\circ} \mathrm{C}$ throughout using an integrated column oven.

168 The mass spectrometer was equipped with a Turbo-V ion source and ESI was operated in negative 169 polarity with multiple reaction monitoring (MRM) scan mode used for detection. Scheduled 170 scanning for specific compounds was carried out according to the expected time of elution, thus 171 improving sensitivity and precision. Nitrogen gas, supplied by a Peak Scientific gas generator, was 172 used as nebulizer, collision and desolvation gas. The two most intense MRM transitions were

173 identified and compound specific parameters including declustering potential, collision energy and

174 collision cell exit potential were optimized by directly infusing each compound at concentrations

175 of $1 \mu \mathrm{g} / \mathrm{ml}$ in methanol into the mass spectrometer. Ion source parameters for each compound were

176 optimized using flow injection analysis with the aim of maximizing signal intensity and stability.

177 The source temperature was set at $600{ }^{\circ} \mathrm{C}$ and gas sources 1 and 2 were set at 35 psi and 40 psi

178 respectively. Ion spray voltage was $-4.5 \mathrm{kv}$ and curtain gas was set at 40 psi.

\section{Method validation}

180 Method validation was conducted by assessing method performance in relation to linearity, limits 181 of detection (LOD), lower limits of quantification (LLOQ), precision and accuracy, and finally

182 matrix effects (ME). Linearity was assessed across a concentration range of 10-1000 ng/ml by 183 generating eight-point calibration curves for each compound of interest. The ratios of the peak 184 areas of the target analytes and their corresponding IS were plotted versus concentration following 
185 duplicate analysis and a weighting of 1/x was applied owing to the large working range. LOD and

186 LLOQ, defined as signal to noise ratio of 3:1 and the lowest concentration of the linear regression

187 respectively, ${ }^{32}$ were assessed after conducting duplicate analysis of blank urine samples fortified

188 to concentrations ranging from $0.001-5 \mathrm{ng} / \mathrm{ml}$. Precision and accuracy were assessed at three

189 concentrations within the working range; $12.5 \mathrm{ng} / \mathrm{ml}$ (low), $550 \mathrm{ng} / \mathrm{ml}$ (medium) and $930 \mathrm{ng} / \mathrm{ml}$

190 (high) for all five compounds. Intra-batch precision was assessed by calculating the \% co-efficient

191 of variation (\% CV) following six repetitions at each concentration. Accuracy was assessed by

192 calculating the mean \% accuracy of the same samples. To assess inter-day precision, \% CV were

193 calculated following six repetitions at each concentration on six days over a three week period.

194 ME, a commonly observed source of error in LC-ESI-MS/MS bioanalysis, were assessed by

195 comparing the analyte peak areas of a neat solution containing $500 \mathrm{ng} / \mathrm{ml}$ of each analyte with

196 those of urine samples, obtained from six different volunteers and fortified to the same

197 concentrations. The \% ME were then calculated as:

198

$$
\% \mathrm{ME}=100 \times\left(\frac{\text { peak area of fortified urine sample }}{\text { peak area of the neat solution }}\right)
$$

199 Stability

200 The optimal mode of sampling in the application of a biomarker approach for assessing LCS

201 intakes may involve the collection of 24-hour urine samples and therefore samples are likely to be

202 kept in potentially sub-optimal storage conditions for longer periods of time prior to final storage

203 and subsequent analysis. Therefore, the stability profiles of the compounds of interest was assessed

204 over a period of 72-hours. To do this, two $1.5 \mathrm{ml}$ aliquots of blank urine samples were fortified to

205 approximately $500 \mathrm{ng} / \mathrm{ml}$ with each of the five compounds of interest and transferred to two amber

206 glass vials. Both were stored in the dark with one sample stored at room temperature while the 
207 other was kept refrigerated at $4{ }^{0} \mathrm{C}$. Aliquots of each sample were taken at five time-points $(0,18$, 20824,48 and 72 hours) and stored at $-80{ }^{\circ} \mathrm{C}$ until analysis.

Dose-response study

210 A double-blind, randomized crossover trial was conducted to assess the usefulness of using urinary

211 excretions to distinguish between different short-term intakes of the five LCSs. A total of 21

212 participants were recruited to the study. Participation lasted three weeks, during which participants

213 were asked to consume three doses of the five LCSs via water-based drinks and to collect both a

214 fasting spot and 24-hour urine sample during each dosing period. The study was approved by the

215 Ulster University Research Ethics Committee (Study No. BMS 014-0095) and a comprehensive

216 description of the study protocol can be found within the supplementary information.

217 In brief, participants' height and weight were measured and they were asked to avoid all of the

218 LCS of interest from at least three days prior to commencing the study to completion, again

219 receiving written literature and verbal advice to aid this. Three doses of the five LCSs of interest,

220 representing $0.1 \%$ (low), $0.5 \%$ (medium) and $10 \%$ (high) of the respective acceptable daily intake

221 (ADI) based on a $70 \mathrm{~kg}$ person, were consumed in a randomized order via two water-based drinks.

222 These doses are relevant to intakes within the free-living population. ${ }^{33}$ Randomization (using

223 Sealed Envelope ${ }^{\mathrm{TM}}$ ) and blinding (by labelling each dose A, B or C) was conducted by a local

224 clinical trials manager who was not part of the current research team. The drinks (500 $\mathrm{ml}$ each)

225 were consumed over two consecutive days at specified times during the three week period and, to

226 blind participants to the dose, $75 \mathrm{ml}$ of an orange cordial (Sainsbury's, UK) was added to each

227 drink during preparation. Participants were purposely advised to consume the test drinks as they

228 preferred across the day to reflect consumption patterns in free-living individuals as much as 
229 possible, with the only stipulation that they consumed one drink $(500 \mathrm{ml})$ per 24-hour period. On

230 the second day of each dosing period, participants collected a morning fasting spot urine sample

231 and a 24-hour urine sample and returned these to the university.

232 All urine samples were processed within two hours of receipt and stored at $-80{ }^{\circ} \mathrm{C}$ until analysis.

233 Urinary biomarker analysis was carried out as described above and PABA analysis was carried

234 out to assess completeness of the 24 -hour urine samples as described elsewhere. ${ }^{30}$ To standardize

235 LCS concentrations in fasting spot urine samples, creatinine concentrations were determined using 236 an ILab 650 (Instrumentation Laboratories, Massachusetts, USA).

\section{Statistical analysis}

238 All data related to method development and validation were acquired and statistically analyzed 239 using Analyst Software Version 1.4.2 (AB Sciex, Warrington, UK) while statistical analysis of the 240 dose-response data was performed using the Statistical Package for Social Sciences (SPSS)

241 Version 22.0 (SPSS UK Ltd, Chersey, United Kingdom). Total LCS excretions were calculated

242 by multiplying the 24 -hour urinary concentrations $(\mathrm{mg} / \mathrm{ml})$ by the volume of the total sample $(\mathrm{ml})$

243 and expressed as $\mathrm{mg} / \mathrm{day}$. Creatinine concentrations in fasting spot urine samples were used to

244 standardize LCS concentrations and values were expressed as $\mu \mathrm{g} / \mathrm{g}$ creatinine. Steviol glycosides

245 are excreted via the urine as steviol glucuronide and therefore values were converted to steviol

246 equivalents; therefore, based on their molecular weights, factors of 0.643 and 0.39 were applied to

247 steviol glucuronide and steviol glycoside values respectively.

248 The distribution of continuous data was assessed using the Shapiro-Wilk test and data which were

249 not normally distributed were log-transformed or non-parametric alternatives were employed.

250 Urinary excretions of all LCSs were skewed and therefore transformation of the data was attempted 
251 prior to carrying out statistical analysis. It was not possible to normalize the distribution of the

252 data; therefore Freidman Tests were used to assess mean differences in excretions across all

253 treatments. Statistically significant results were followed up with Wilcoxon Signed Rank Tests to

254 identify where the differences were. Bonferroni adjustment was applied to the alpha values in post-

255 hoc Wilcoxon Signed Rank Tests to control for Type 1 errors as a result of multiple comparisons

256 and therefore an alpha level of 0.017 (0.05/number of comparisons) was considered significant.

257 Spearman correlations were carried out to assess co-linearity between the dose of LCS ingested

258 and urinary excretions (both 24-hour urine and fasting spot sample). Standard multiple regression

259 was then used to assess the ability of 24-hour urinary excretion of the five compounds of interest

260 to predict intake after controlling for age, gender and body mass index (BMI). A P-value of $<0.05$

261 was considered statistically significant unless otherwise stated.

\section{Results and Discussion}

263 Improved assessment of LCS intakes is necessary to properly investigate relationships between

264 LCS use and health. To this end, a LC-ESI-MS/MS method was developed and validated for the

265 simultaneous determination of five commonly used LCSs in human urine. Although numerous

266 methods have been published describing the simultaneous determination of various combinations

267 of LCSs in matrices such as foods, beverages and water sources, ${ }^{15,24-27}$ the method described here

268 is the first which simultaneously determines these particular LCSs as they are excreted via urine.

269 As an initial biomarker validation step, the method was applied in a dose-response study to assess

270 the usefulness of using urinary excretions to assess recent intakes.

\section{Method performance}


272 The general characteristics, including the chemical structures of the five compounds of interest,

273 are presented in Table 1 . Single spectral peaks corresponding to $[\mathrm{M}-\mathrm{K}]^{-}$for acesulfame-K, $[\mathrm{M}-$

$274 \mathrm{Na}^{-}$for sodium saccharin and sodium cyclamate and [M-H] ${ }^{-}$for sucralose and steviol glucuronide

275 were observed. Table 2 presents the two MRM transitions used for quantitative and qualitative

276 purposes, the corresponding IS and the collision energy for each MRM transition. The most intense

277 transition for each compound was used for quantification. In contrast to a previous study by Yang

278 and Chen, ${ }^{34}$ which utilized MS only, the utilization of MS/MS in this study allowed for increased

279 specificity and sensitivity which is important in bioanalysis. As has been reported elsewhere in

280 the literature, the signal intensity for sucralose was lower than for the other analytes and post-

281 column infusion of TRIS-buffer has previously been used to enhance the signal for sucralose. ${ }^{24}$

282 However for the purposes of our method, and the desired working range, the signal was deemed

283 adequate without the need for further enhancement.

284 Good base peak separation was observed for the five compounds (Fig. 1). Previous methods have 285 incorporated solid phase extraction ${ }^{24,26}$ or liquid-liquid extraction ${ }^{34}$ in sample preparation which 286 may make the application of such methods less feasible for large numbers of samples, whereas the

287 simple procedure described above lends itself better to a high throughput application. However, 288 with minimal sample clean-up prior to introduction to the mass spectrometer, the integrated 289 diverter valve was used to direct flow to waste outside the expected elution times and thereby 290 protecting the mass spectrometer from excessive contamination. Various concentrations of 291 methanol (2-15\%) in MP-A were assessed and when the concentration was increased to $10 \%$ or 292 above acesulfame-K eluted close to the void volume; therefore 5\% was considered suitable.

\section{Method validation}


294 Results for linearity, LOD and LLOQ, and precision and accuracy are presented in Table 2. 295 Excellent linearity was observed for all five compounds over the desired concentration range of $29610-1000 \mathrm{ng} / \mathrm{ml}$ with coefficients of determination $\left(r^{2}\right)$ ranging from 0.9969 to 0.9997 . Mean 297 accuracy ranged from $98 \%$ to $104 \%$ at low concentrations while at high concentrations, accuracy 298 ranged from $92 \%$ to $102 \%$. The use of stable isotopes as IS for acesulfame-K, sodium saccharin, 299 sodium cyclamate and sucralose resulted in excellent levels of accuracy (99-103\%) and precision 300 with \% CV below $7.7 \%$ at all three concentrations assessed (i.e. $15 \mathrm{ng} / \mathrm{ml}, 550 \mathrm{ng} / \mathrm{ml}$ and 930 $301 \mathrm{ng} / \mathrm{ml}$ ). For steviol glucuronide, warfarin sodium was used as IS as this has been previously used 302 for LC-MS analysis of LCSs. ${ }^{34}$ Accuracy and precision for steviol glucuronide fell within 303 acceptable limits, albeit the use of the stable isotope of this compound as IS in future analyses 304 would likely improve these figures further.

305 Prior to the assessment of the presence of ME, screening of 'blank' urine samples revealed traces 306 of several of the compounds of interest and therefore duplicate runs of all six samples were carried 307 out prior to analysis of the fortified samples so that corrections could be applied. The average area 308 of each observed peak in the pre-fortified samples was recorded and the results were subsequently 309 corrected. Mean \% ME ranged from $89 \%$ to $99 \%$ for acesulfame-K, $80 \%$ to $100 \%$ for saccharin, $31089 \%$ to $104 \%$ for cyclamate, $87 \%$ to $99 \%$ for sucralose and $94 \%$ to $107 \%$ for steviol glucuronide.

311 These results suggest the existence of interfering compounds within some urine samples,

312 potentially introducing a source of inaccuracy and/or imprecision if neat solutions were used as 313 calibration and QC standards. However, with the use of IS, \% CV within urine samples were below $3145.5 \%$ for all five compounds and therefore all calibration and QC samples were prepared using 315 blank urine samples. As such, the potentially deleterious effects of ME were largely minimized.

\section{Stability}


317 Acesulfame, saccharin, cyclamate and sucralose have recently been identified as potential aquatic

318 contaminants owing to their persistence in the environment ${ }^{23}$ and therefore good stability was 319 expected over the 72-hour test period. However the stability profile of steviol glucuronide was less

320 well known. Indeed, acesulfame-K, saccharin, cyclamate and sucralose did not undergo any

321 detectable degradation over the 72-hour period either when stored at room temperature or when

322 refrigerated. A small, yet non-significant $(\mathrm{p}=0.312)$, degree of degradation $(\sim 8 \%)$ was observed 323 for steviol glucuronide when stored at room temperature for up to 72-hours.

\section{Dose-response study}

\section{Participants and urine collections}

326 No significant differences were observed between males and females with respect to age, weight,

327 BMI or volume of 24-hour urine samples (Table 3). During the dose-response study, participants

328 consumed three different amounts $(0.1 \%, 0.5 \%$ and $10 \%$ of the ADI based on a $70 \mathrm{~kg}$ person) of

329 the five LCSs comparable to what has been observed within the free-living population, ${ }^{22,33}$ while 330 avoiding the five LCSs in their diet. A total of 84 24-hour urine samples were collected (four per 331 participant) and of these, $55(65.5 \%)$ were considered complete based on PABA excretion and/or 332 participant reporting. Mean urinary concentrations (based on fasting spot samples) and daily 333 excretion (based on 24-hour samples) following each dosing period are presented in Table 4.

\section{Biomarker validation}

335 Mean urinary concentrations of all five compounds were significantly correlated with intakes of 336 the respective LCS; the correlations for 24-hour urinary acesulfame-K, saccharin, cyclamate, 337 sucralose and steviol glucuronide were $0.909(\mathrm{p}<0.001), 0.888(\mathrm{p}<0.001), 0.942(\mathrm{p}<0.001)$, $3380.512(\mathrm{p}=0.001)$ and $0.942(\mathrm{p}<0.001)$ respectively. Correlations for fasting spot urinary 
339 concentrations of acesulfame-K, saccharin, cyclamate, sucralose and steviol glucuronide were

$3400.823(\mathrm{p}<0.001), 0.874(\mathrm{p}<0.001), 0.818(\mathrm{p}<0.001), 0.410(\mathrm{p}=0.007)$ and $0.887(\mathrm{p}<0.001)$

341 respectively. Until now, the dose-response relationship between intake and urinary excretion has

342 only been investigated for acesulfame-K and saccharin when strong correlations were also

343 observed between 24-hour urinary excretion and intakes $\left(r^{2}=0.9912\right.$ for acesulfame-K and $r^{2}=$

3440.9963 for saccharin) during an acute intake/excretion study. ${ }^{19}$

345 In relation to 24-hour urine samples, mean recoveries from the low, medium and high doses were $34698 \%, 89 \%$ and $85 \%$ for acesulfame-K, $100 \%, 79 \%$ and $86 \%$ for saccharin, $24 \%, 28 \%$ and $25 \%$ for

347 cyclamate and $86 \%, 52.7 \%$ and $47 \%$ for steviol glycosides (see Table 4 for absolute recoveries).

348 Higher than expected levels of recovery of sucralose were observed at the lower doses $(450 \%$,

$349100 \%$ for low and medium respectively) as it was present in the cordial used in the LCS drinks

350 and this is discussed in more detail later. For the high dose of sucralose, mean recovery was $8 \%$

351 while previous work investigating the pharmacokinetics of sucralose reported an average excretion

352 of $13 \%$ of a dose in urine within the first 24 -hours post-ingestion. ${ }^{20}$ For acesulfame-K and

353 saccharin the majority of the dose was recovered which is in agreement with results reported

354 elsewhere, ${ }^{35-37}$ although one study reported an average recovery of $68 \%$ of an acesulfame-K dose

355 in 24-hour urine samples. ${ }^{19}$ In contrast to acesulfame-K and saccharin, only partial recoveries were

356 observed in the 24-hour urinary samples for cyclamate (24-28\%) and steviol glycosides (47-86\%).

357 Previous pharmacokinetic investigations of cyclamate primarily focused on its metabolite, 358 cyclohexylamine, as approximately $20 \%$ of the population have the ability, to varying degrees, to 359 convert cyclamate to cyclohexylamine via bacterial hydrolysis. Chronic exposure has been shown 360 to enhance conversion in some individuals, ${ }^{38}$ however, conversion only occurs to the unabsorbed 361 proportion reaching the colon and therefore does not affect the absorbed proportion of cyclamate. ${ }^{39}$ 
362 Steviol glycosides also undergo bacterial hydrolysis in the gut and are absorbed into the body as

363 steviol which subsequently undergoes conjugation before excretion via the urine as steviol

364 glucuronide. ${ }^{40}$ Previously it has been reported that approximately $34 \%$ of a dose is excreted in the

365 urine over 24 -hours ${ }^{41}$ which is much lower than what was observed as part of this work which

366 observed typical excretion of $47-86 \%$ over the same period. A possible explanation is the dose in

367 the previous study was significantly larger than in the present work.

368 Both modes of sampling were useful for distinguishing between all three intakes tested in the 369 present study for acesulfame-k $(\mathrm{p}<0.001)$, saccharin $(\mathrm{p}<0.001)$, cyclamate $(\mathrm{p}<0.001)$ and steviol 370 glycosides $(\mathrm{p}<0.001)$ (Table 4). It is particularly noteworthy that fasting spot urine samples are

371 useful as the collection of such samples would be less invasive for participants, making the

372 application of a biomarker approach in larger-scale population based studies more feasible.

373 However, further validation work with a larger sample size would help to confirm the usefulness

374 of fasting spot samples for distinguishing between different intakes. In relation to sucralose, it was

375 possible to use both the fasting spot and 24-hour urinary sucralose excretions to distinguish the 376 high dose from both the low and medium doses $(\mathrm{p}<0.001)$ but not the low and medium doses $(\mathrm{p}$ $377=0.198)$. The presence of sucralose in the cordial used for the LCS drinks is likely to have biased

378 the results at the lower doses and therefore further work, with proper wash-out periods, would 379 facilitate more comprehensive investigations of the dose-response relationship for sucralose.

380 Given that 24-hour urinary excretions allow for calculation of overall daily excretion, regression 381 analysis using the LCS dose as a dependent variable and 24-hour urinary concentrations as an 382 independent variable were conducted and 24-hour excretions explained $99 \%$ of the variability for 383 acesulfame-K $\left(\mathrm{F}(1,39)=2302.32\right.$, adjusted $\left.r^{2}=0.987, \mathrm{p}<0.001\right), 87 \%$ of the variability for 384 saccharin $\left(\mathrm{F}(1,39)=261.75\right.$, adjusted $\left.r^{2}=0.870 \mathrm{p}<0.001\right), 91 \%$ of the variability for cyclamate 
$385\left(\mathrm{~F}(1,39)=419.23\right.$, adjusted $\left.r^{2}=0.913 \mathrm{p}<0.001\right), 35 \%$ of the variability for sucralose $(\mathrm{F}(1,39)$

$386=22.59$, adjusted $\left.r^{2}=0.350 \mathrm{p}<0.001\right)$ and $75 \%$ of the variability for steviol glycosides $(\mathrm{F}(1,39)$

$387=118.09$, adjusted $\left.r^{2}=0.745 \mathrm{p}<0.001\right)$. Such findings would suggest that 24-hour urinary

388 excretions may be useful for estimating absolute intakes of the respective LCS.

389 A number of limitations with the present work should be acknowledged. The presence of sucralose

390 in the cordial used in the LCS drink prevented a comprehensive investigation of the relationship

391 between sucralose consumption and urinary excretion. The cordial was chosen as no LCS-free

392 cordial could be sourced at the time of conducting the study and therefore measures were taken to

393 control for this by maintaining a consistent dose of cordial added to the LCS drink. However, no

394 account was taken of the possible variation in sucralose concentrations within the product which

395 may have contributed to variation in the results. Despite the presence of sucralose in the cordial, a

396 high intake of sucralose was shown to result in higher mean excretions as compared with the low

397 or medium intakes in both modes of sampling; as such, urinary excretions of sucralose may be

398 useful in distinguishing between low and high consumers which, nevertheless, may be of most

399 clinical interest. A further consideration is that the present studies only investigated urinary

400 concentrations following short-term intakes (over two consecutive days) and in individuals who

401 were actively avoiding LCSs. Further work to assess the usefulness of a biomarker approach in

402 regular and potentially high LCS consumers, such as those with diabetes mellitus or children, is

403 warranted. Moreover, investigations of the long-term reproducibility of these biomarkers,

404 specifically aiming to establish the required number of samples to determine habitual intakes are

405 warranted to better characterize the relationship between intakes and urinary excretions.

406 A novel urinary biomarker approach for assessing recent intakes of five commonly consumed

407 LCSs has been presented. Such an approach will help generate more objective LCS intake data 
408 when applied in population-based studies, representing an opportunity to significantly enhance our

409 understanding of the relationship between LCSs and human health.

\section{Abbreviations used}

411 Ace-d4, acesulfame-d4 potassium salt; ADI, acceptable daily intake; Cyc-d11, cyclohexyl-d11;

412 ESI, electrospray ionization; EU, European Union; FFQs, food frequency questionnaires; HPLC,

413 high performance liquid chromatography; IS, internal standard; LCS, low-calorie sweetener; LC-

414 ESI-MS/MS, liquid chromatography tandem-mass spectrometry; LC-MS, liquid chromatography

415 mass spectrometry; MRM, multiple reaction monitoring; PABA, paraminobenzoic acid; Sac-d4, 416 saccharin-d4; Suc-d6, sucralose-d6.

\section{Acknowledgement}

418 We would like to thank Eddie O'Kane for technical assistance throughout method development.

\section{Supporting information description}

420 The Supporting Information is available free of charge on the ACS Publications website at DOI:

$421 \quad \operatorname{xxxx}$

422 Description of the dose-response study protocol; the doses administered to participants in the dose423 response study (Table S-1).

\section{Funding}

425 This work was funded by the National Institute for Public Health and the Environment (RIVM) in 426 The Netherlands. 
1. Butland, B.; Jebb, S.; Kopelman, P.; McPherson, K.; Thomas, S.; Mardell, J.; Parry, V.; Foresight, Tackling Obesities: Future Choices- Project Report; 2nd Edition; UK Government for Science, 2007.

2. Finucane, M. M.; Stevens, G. A.; Cowan, M. J.; Danaei, G.; Lin, J. K.; Paciorek, C. J.; Singh, G. M.; Gutierrez, H. R.; Lu, Y.; Bahalim, A. N.; Farzadfar, F.; Riley, L. M.; Ezzati, M. National, regional, and global trends in body-mass index since 1980: systematic analysis of health examination surveys and epidemiological studies with 960 country-years and 9.1 million participants. Lancet. 2011, 377, 557-567.

3. Fryar, C.D.; Carroll, M.D.; Ogden, C.L. Prevalence of Overweight, Obesity, and Extreme Obesity among Adults: United States, 1960-1962 through 2011-2012; National Center for Health Statistics, Division of Health and Nutrition Examination Surveys. [Online] 2014, http://www.cdc.gov/nchs/data/hestat/obesity_adult_11_12/obesity_adult_11_12.htm (accessed March 4, 2015).

4. World Health Organisation. Obesity and Overweight Fact sheet No 311. WHO Media Centre [Online] 2015, http://www.who.int/mediacentre/factsheets/fs311/en/ (accessed May 15, 2015).

5. World Health Organisation Guideline: Sugars intake for adults and children. [Online] 2015, http://apps.who.int/iris/bitstream/10665/149782/1/9789241549028_eng.pdf （accessed October 2, 2016).

6. Scientific Advisory Committee on Nutrition (SACN) (2015) Carbohydrates and Health. [Online] 

https://www.gov.uk/government/uploads/system/uploads/attachment_data/file/445503/S ACN_Carbohydrates_and_Health.pdf (accessed January 11, 2016).

7. Grenby, T.H. Update on low-calorie sweeteners to benefit dental health. Int. Dent. J. 1991, 41, 217-224.

8. Rodgers, P. J.; Hognkamp, P. S.; de Graaf, C.; Higgs, S.; Lluch, A.; Ness, A. R.; Penfold, C.; Perry, R.; Putz, P.; Yeomans, M. R.; Mela, D. J. Does low-energy sweetener consumption affect energy intake and body weight? A systematic review, including metaanalyses, of the evidence from human and animal studies. Int. J. Obes. 2016, 40, 387-394.

9. Swithers, S. E. Artificial sweeteners produce the counterintuitive effect of inducing metabolic derangements. Trends Endocrinol. Metab. 2013, 24, 431-441

10. Imamura, F.; O’Connor, L.; Ye, Z.; Mursu, J.; Hayashino, Y.; Bhupathiraju, S. N.; Forouhi, N. G. Consumption of sugar sweetened beverages, artificially sweetened beverages, and fruit juice and incidence of type 2 diabetes: systematic review, meta-analysis, and estimation of population attributable fraction. Br. J. Sports Med. 2016, 50, 496-504. D. V.; Almeda-Valdes, P. Effects of non-nutritive sweeteners on glucose metabolism and appetite regulating hormones: Systematic review of observational prospective studies and clinical trials. PLoS ONE 2016, 11, e0161264. Doi: 10.1371/journal.pone.0161264. Lichtenstein, A. H. Nonnutritive sweeteners: current use and health perspectives. Diabetes Care 2012, 35, 1798-1808.

13. Burke, M. V.; Small, D. M. Physiological mechanisms by which non-nutritive sweeteners may impact body weight and metabolism. Physiol. Behav. 2015, 152 (Pt B), 381-388. 

Opinion on the assessment of the nutritional benefits and risks related to intense https://www.anses.fr/en/system/files/NUT2011sa0161RaEN.pdf (accessed February 23, 2015).

15. Lange, T.; Scheurer, M.; Brauch, H. J. Artificial sweeteners- a recently recognised class of emerging environmental contaminants: a review. Anal. Bioanal. Chem. 2012, 403, 2503 2518.

16. Bingham, S. A. Biomarkers in nutritional epidemiology. Public Health Nutr. 2002, 5, 821827.

17. Landberg, R.; Aman, P.; Friberg, L. E.; Vessby, B.; Adlercreutz, H.; Kamal-Eldin, A. Dose-response of whole-grain biomarkers: alkylresorcinols in human plasma and their metabolites in urine in relation to intake. Am. J. Clin. Nutr. 2009, 89, 290-296.

18. Renwick, A.G. (1986) The metabolism of intense sweeteners. Xenobiotica, 1986, 16 (10/11), 1057-1071.

19. Wilson, A. L; Wilkinson, K.; Crews, H. M.; Davies, A. M.; Dick, C. S.; Dumsday, V. L.

21. Geuns, J. M. C.; Buyse, J.; Vankeirsbilck, A.; Temme, E. H. M.; Compernolle, F.; Toppet, S. Identification of steviol glucuronide in human urine. J. Agric. Food Chem. 2006, 54, 2794-2798. 
22. Logue, C.; Dowey, L.C..; Strain, J.J.; Verhagen, H.; Gallagher, A.M. The potential application of a biomarker approach to investigate low-calorie sweetener exposure. Proc. Nutr. Soc. 2016, 75(2), 216-225. epidemiology: applications, needs and new horizons. Hum. Genet. 2009, 125, 507-525. sweeteners in German waste water and surface water and in soil aquifer treatment (SAT). Anal. Bioanal. Chem. 2009, 394 (6), 1585-1594.

25. Zygler, A.; Wasik, A.; Namiesnik, J. Analytical methodologies for determination of artificial sweeteners in foodstuffs. TrAC, Trends Anal. Chem. 2009, 28 (9), 1082-1102. in water samples by solid-phase extraction and liquid chromatography-tandem mass spectrometry. J. Chromatogr. A, 2012, 1256, 197-205.

27. Ens, W.; Senner, F.; Gygax, B. Development, validation and application of a novel LCMS/MS trace analysis method for the simultaneous quantification of seven iodinated Xray contrast media and three artificial sweeteners in surface, ground, and drinking water. Anal. Bioanal. Chem. 2014, 406, 2789-2798.

28. Kuhnle, G. Nutritional biomarkers for objective dietary assessment. J. Sci. Food Agric. 2012, 92, 1145-1149.

29. Bingham, S.; Cummings, J. H. The use of 4-aminobenzoic acid as a marker to validate the completeness of $24 \mathrm{~h}$ urine collections in man. Clin. Sci. 1983, 64, 629-635.

30. Jakobsen, J.; Ovesen, L.; Fagt, S.; Pedersen, A. N. Para-aminobenzoic acid used as a marker for completeness of 24 hour urine: assessment of control limits for a specific HPLC method. Eur. J. Clin. Nutr. 1997, 51, 514-519. 
31. Agilent Technologies. Analysing Synthetic Sweeteners in Waste Water with Robust Sample Preparation. Application Note (Environmental), [Online] 2011, http://www.chem.agilent.com/Library/applications/5990-8248EN.pdf. (accessed March 23, 2013).

32. US Food and Drug Administration (FDA) Guidance for Industry, Bioanalytical Method Validation 2001.

33. Renwick, A. G. The intake of intense sweeteners- an update review. Food Addit. Contam. 2006, 23 (4), 327-338.

34. Yang, D. J.; Chen, B. Simultaneous determination of nonnutritive sweeteners in foods by HPLC/ESI-MS. J. Agric. Food Chem. 2009, 57, 3022-3027.

35. Christ, O.; Rupp, W. Human experiments with Acetosulfam- ${ }^{14} \mathrm{C}$. Pharmacokinetics after oral administration of 30mg to three healthy male probands. 1976, Unpublished report. In Acesulfame Potassium. WHO Food Additives Series 28. [Online] http://www.inchem.org/documents/jecfa/jecmono/v28je13.htm (accessed June 3, 2015).

36. Ball, L. M.; Renwick, A. G.; Williams, A. G. The fate of $\left[{ }^{14} \mathrm{C}\right]$ saccharin in man, rat and rabbit and of 2-sulphamoyl $\left[{ }^{14} \mathrm{C}\right]$ benzoic acid in the rat. Xenobiotica, 1977, 7, 189-203.

37. Sweatman, T. W.; Renwick, A. G.; Burgess, C. D. The pharmacokinetics of saccharin in man. Xenobiotica, 1981, 11, 531-540.

38. Renwick, A. G.; Thompson, J. P.; O'Shaughnessy, M.; Walter, E. J. The metabolism of cyclamate to cyclohexylamine in humans during long-term administration. Toxicol. Appl. Pharmacol. 2004, 196, 367-380.

39. Bopp, B. A.; Sonders, R. C.; Kesterson, J. W. Toxicological aspects of cyclamate and cyclohexylamine. Crit. Rev. Toxicol. 1986, 16(3), 213-306.

40. Wheeler, A.; Boileau, A. C.; Winkler, P. C.; Compton, J. C.; Jiang, X.; Mandarino, D. A. Pharmacokinetics of rebaudioside A and stevioside after single oral doses in healthy men. Food Chem. Toxicol. 2008, 46, S54-S60.

41. Geuns, J. M. C.; Buyse, J.; Vankeirsbilck, A.; Temme, E. H. M. Metabolism of stevioside by healthy subjects. Exp. Biol. Med. 2007, 232, 164-173. 


\section{Figure captions}

548 Figure 1. LC-ESI-MS/MS chromatogram of a single analysis of spiked urine sample depicting the

549 most intense MRM transition for each compound. (a) acesulfame-k, m/z 162/82, (b) sodium

550 saccharin, m/z 182/42, (c) sodium cyclamate, m/z 178/80, (d) sucralose, m/z 395/35, (e) steviol

551 glucuronide, $\mathrm{m} / \mathrm{z}$ 493/317.

552 Figure 2. Urinary excretion (a, 24-hour; b, fasting spot) of (i) acesulfame-K, (ii) saccharin, (iii)

553 cyclamate, (iv) sucralose and (v) steviol following low, medium and high doses which were

554 consumed in a randomized order. ${ }^{a}$ Doses equated to $0.1 \%$ (low), $0.5 \%$ (medium) and $10 \%$ (high)

555 of the acceptable daily intake based on a $70 \mathrm{~kg}$ person. 
Table 1. General characteristics of acesulfame-K, sodium saccharin, sodium cyclamate, sucralose and steviol glucuronide.

\begin{tabular}{|c|c|c|c|c|}
\hline Compound & Cas No & Sweetness $^{a}$ & Structure & $\begin{array}{l}\text { Monoisotopic } \\
\text { mass (Da) }\end{array}$ \\
\hline Acesulfame-K & $55589-62-3$ & 200 & i & 200.95 \\
\hline Sodium saccharin & $82385-42-0$ & $300-500$ & & 204.98 \\
\hline Sodium cyclamate & $139-05-9$ & 30 & & 201.04 \\
\hline Sucralose & $56038-13-2$ & 600 & & 396.01 \\
\hline $\begin{array}{l}\text { Steviol } \\
\text { glucuronide }\end{array}$ & $\mathrm{N} / \mathrm{A}^{b}$ & $\mathrm{~N} / \mathrm{A}^{b}$ & & $494.57^{c}$ \\
\hline
\end{tabular}

\footnotetext{
${ }^{a}$ Sweetness relative to sucrose. ${ }^{b}$ N/A, not applicable. ${ }^{c}$ Average molar mass. Da, daltons.
} 
Table 2. Method characteristics, limits of detection and quantification and coefficients of determination.

\begin{tabular}{|c|c|c|c|c|c|c|c|}
\hline Compound & $\begin{array}{l}\text { Retention } \\
\text { time (min) }\end{array}$ & $\begin{array}{l}\text { MRM transitions } \\
(\mathrm{m} / \mathrm{z})\end{array}$ & $\begin{array}{l}\text { Collision } \\
\text { energy }(\mathrm{eV})\end{array}$ & $\begin{array}{l}\text { Internal standard } \\
(\mathrm{m} / \mathrm{z})\end{array}$ & $\begin{array}{l}\text { LOD } \\
(\mathrm{ng} / \mathrm{ml})\end{array}$ & $\begin{array}{l}\text { LLOQ } \\
(\mathrm{ng} / \mathrm{ml})\end{array}$ & $r^{2}$ \\
\hline Acesulfame-K & 2.0 & $\begin{array}{l}162 / 82^{a} \\
162 / 78\end{array}$ & $\begin{array}{l}-21 \\
-44\end{array}$ & Ace-d4 (166/86) & 0.01 & 10.0 & 0.9997 \\
\hline Sodium saccharin & 3.8 & $\begin{array}{l}182 / 42^{a} \\
182 / 106\end{array}$ & $\begin{array}{l}-42 \\
-24\end{array}$ & Sac-d4 (186/42) & 0.06 & 10.0 & 0.9994 \\
\hline Sodium cyclamate & 4.7 & $\begin{array}{l}178 / 80^{a} \\
178 / 96\end{array}$ & $\begin{array}{l}-42 \\
-32\end{array}$ & Cyc-d11 (189/80) & 0.02 & 10.0 & 0.9992 \\
\hline Sucralose & 6.7 & $\begin{array}{l}395 / 35^{a} \\
395 / 359\end{array}$ & $\begin{array}{l}-32 \\
-14\end{array}$ & Suc-d6 (401/35) & 0.40 & 10.0 & 0.9969 \\
\hline Steviol glucuronide & 10.4 & $\begin{array}{l}493 / 317^{a} \\
493 / 113\end{array}$ & $\begin{array}{l}-32 \\
-30\end{array}$ & Warfarin $\mathrm{Na}(307 / 307)$ & 0.01 & 10.0 & 0.9991 \\
\hline
\end{tabular}

${ }^{a}$ Transition used for quantification. Limit of detection (LOD) defined as a signal to noise ratio of 3:1. Lower limit of quantification (LLOQ) defined as lowest amount of an analyte in a sample that can be quantitatively determined with suitable precision and accuracy. $r^{2}$ for concentration ranges of $10-1000$ ng/ml. MRM, multiple reaction monitoring; Ace-d4, acesulfame-d4 potassium salt; Sac-d4, saccharin-d4; Cyc-d11, cyclamate-d11; Suc-d6, sucralose-d6; Warfarin $\mathrm{Na}$, Warfarin sodium. 
Table 3. General characteristics of participants taking part in the doseresponse study. ${ }^{a}$

\begin{tabular}{|c|c|c|c|c|}
\hline & Overall & $\begin{array}{l}\text { Males } \\
n 10\end{array}$ & $\begin{array}{l}\text { Females } \\
n 11\end{array}$ & $P$ value $^{b}$ \\
\hline Age (years) & $25.7(4.9)$ & $26.3(3.7)$ & $25.1(5.8)$ & 0.173 \\
\hline Height (m) & $1.7(0.09)$ & $1.78(0.05)$ & $1.64(0.07)$ & $<0.001$ \\
\hline Weight (kg) & 71.4 (11.9) & $77.5(10.6)$ & $65.8(10.6)$ & 0.021 \\
\hline $\begin{array}{l}\text { Body mass index } \\
\left(\mathrm{kg} / \mathrm{m}^{2}\right)\end{array}$ & $24.7(3.4)$ & $24.7(2.8)$ & $24.6(4.0)$ & 0.947 \\
\hline \multicolumn{5}{|l|}{ Urine volume $(\mathrm{ml})$} \\
\hline Time-point $1^{c}$ & 2024 (759) & $1859(736)$ & $2174(783)$ & 0.355 \\
\hline Time-point $2^{c}$ & $1957(865)$ & $1784(708)$ & $2114(994)$ & 0.396 \\
\hline Time-point $3^{c}$ & $2086(834)$ & $1831(556)$ & $2319(995)$ & 0.188 \\
\hline
\end{tabular}

${ }^{a}$ Values are mean (SD).

${ }^{b}$ Statistical analyses were carried out to investigate differences between males and females. Age was assessed with Mann U Whitney test; height, weight, body mass index and urine volume were assessed with Independent Samples t-test.

${ }^{c}$ Time-points refer to 24 -urine collections after each dosing period. 
Table 4. Mean urinary excretions of acesulfame-K, saccharin, cyclamate, sucralose and steviol following low, medium and high doses of the respective low-calorie sweetener. ${ }^{a}$

\begin{tabular}{|c|c|c|c|c|}
\hline & $0.1 \%$ ADI & $0.5 \%$ ADI & $10 \% \mathrm{ADI}$ & $P$ value ${ }^{b}$ \\
\hline $\begin{array}{l}\text { 24-hour urine sample } \\
\text { (mg/day) }\end{array}$ & $n=14$ & $n=13$ & $n=12$ & \\
\hline Acesulfame-K & $0.59(0.09)$ & $2.85(0.30)^{*}$ & $52.56(5.33)^{*}$ & $<0.001$ \\
\hline Saccharin & $0.40(0.32)$ & $1.34(0.37)^{*}$ & $29.51(9.72)^{*}$ & $<0.001$ \\
\hline Cyclamate & $0.12(0.05)$ & $0.54(0.13)^{*}$ & $10.99(2.92)^{*}$ & $<0.001$ \\
\hline Sucralose & $5.40(2.07)$ & $5.20(1.58)$ & $9.23(3.92)^{*}$ & $<0.001$ \\
\hline Steviol & $0.23(0.04)$ & $0.72(0.29)^{*}$ & $12.70(5.54)^{*}$ & $<0.001$ \\
\hline $\begin{array}{l}\text { Spot urine sample } \\
\text { ( } \mu \mathrm{g} / \mathrm{g} \text { creatinine })\end{array}$ & $n=19$ & $n=19$ & $n=19$ & \\
\hline Acesulfame-K & $455(836)$ & $1396(1331)^{*}$ & $31983(34562)^{*}$ & $<0.001$ \\
\hline Saccharin & $210(304)$ & $1171(1650)^{*}$ & $18408(15562)^{*}$ & $<0.001$ \\
\hline Cyclamate & $71(89)$ & $470(904)^{*}$ & $7569(6494)^{*}$ & $<0.001$ \\
\hline Sucralose & $3453(6644)$ & $2668(2210)$ & $5493(5159)^{*}$ & $<0.001$ \\
\hline Steviol & $146(106)$ & $905(799)^{*}$ & $13913(13956)^{*}$ & $<0.001$ \\
\hline \multicolumn{5}{|c|}{$\begin{array}{l}{ }^{a} \text { Values represent means (SD); ADI, acceptable daily intake. Low, medium and high doses represent } 0.1 \%, 0.5 \% \\
\text { and } 10.0 \% \text { of the ADI for a } 70 \mathrm{~kg} \text { person. } \\
{ }^{b} \text { Freidman Tests carried out to compare means urinary concentrations across all time-points. Wilcoxon Signed } \\
\text { Rank tests then carried out as post-hoc analysis to determine where the differences were with Bonferroni } \\
\text { adjustment applied to control for multiple comparisons; as such } P \text { value of }<0.017 \text { was considered as significant. } \\
* \text { denotes a statistically significant difference with the immediate lower dose. }\end{array}$} \\
\hline
\end{tabular}


Figure graphics

Figure 1

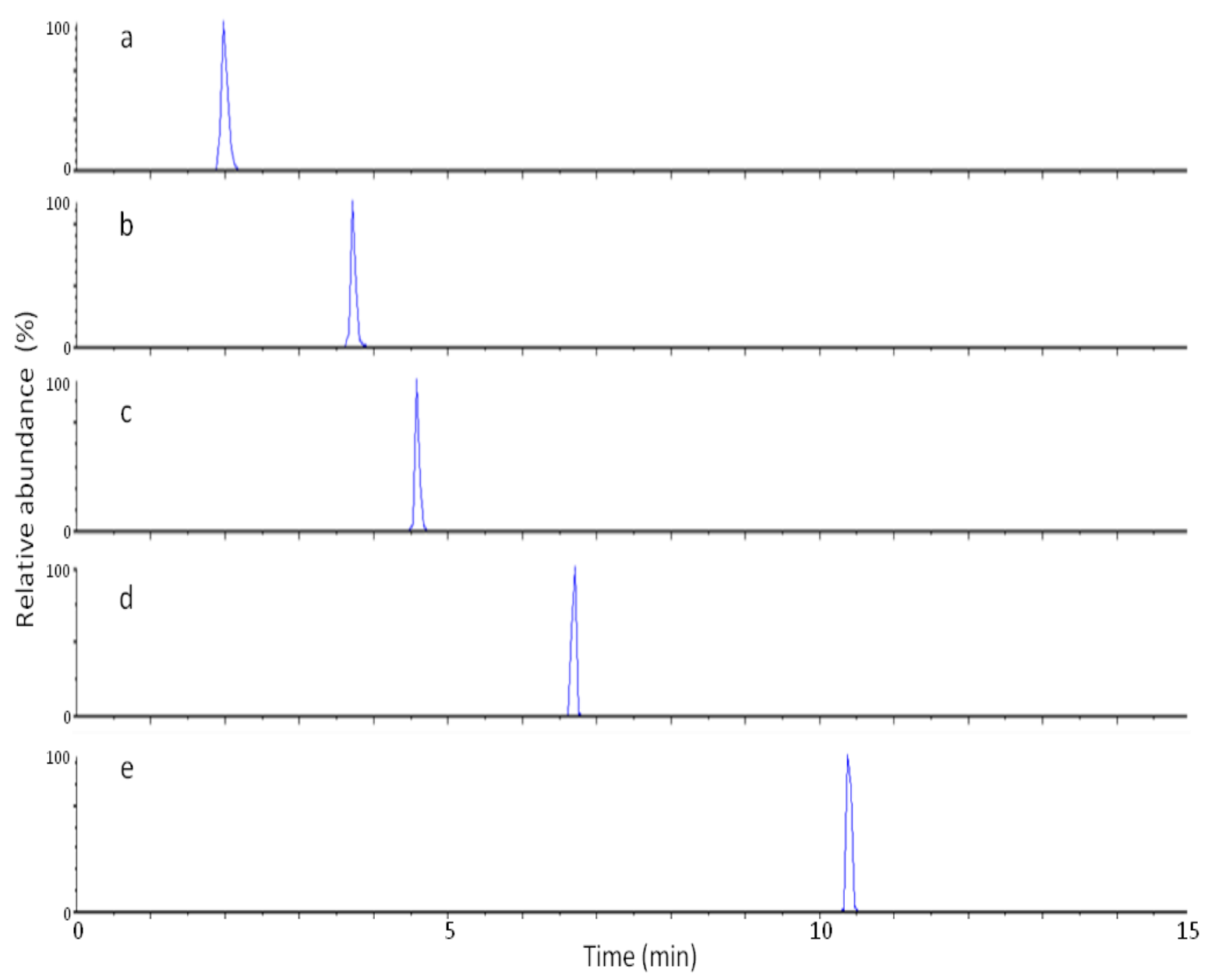




\section{Figure 2}
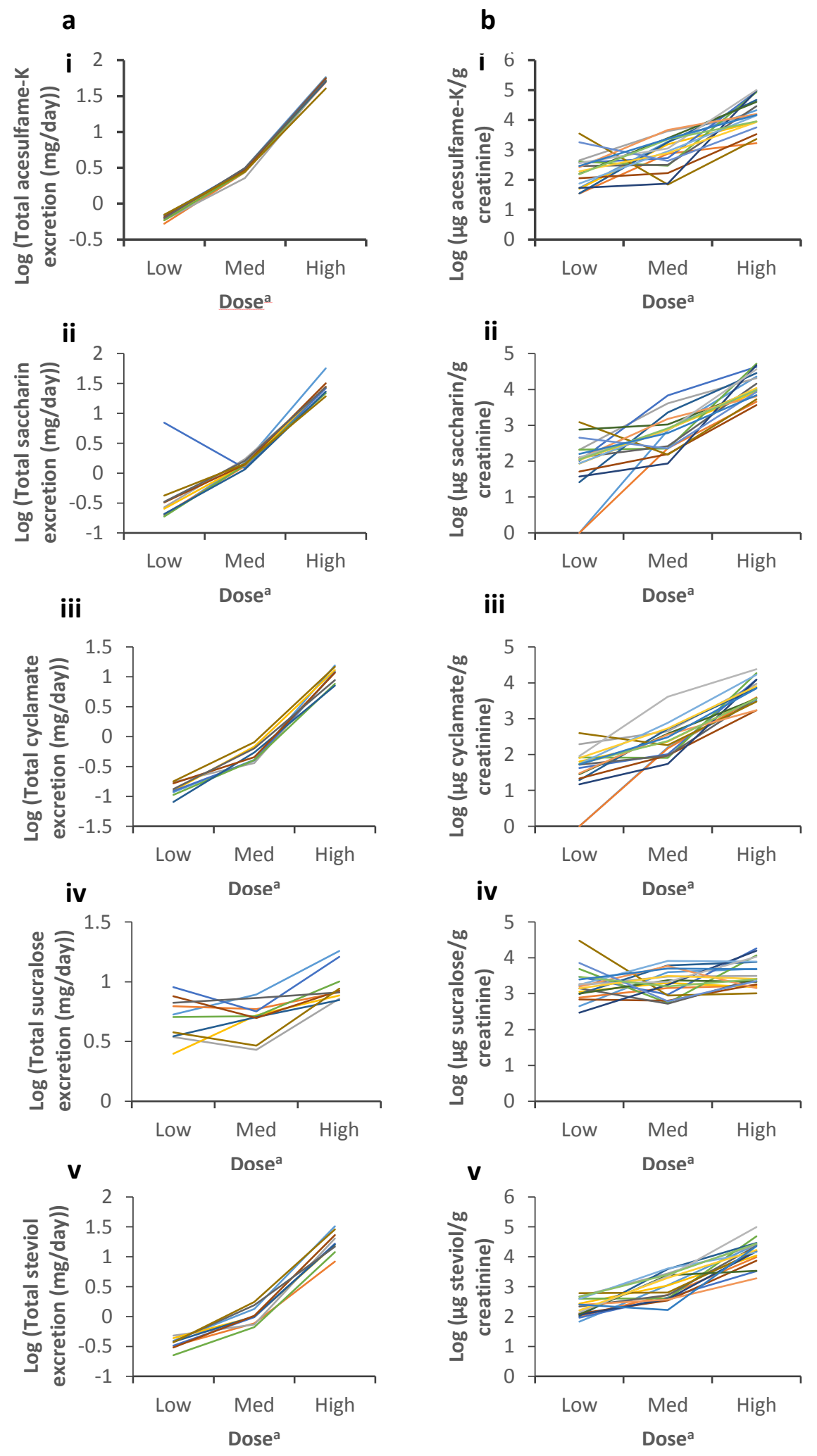
For table of contents only

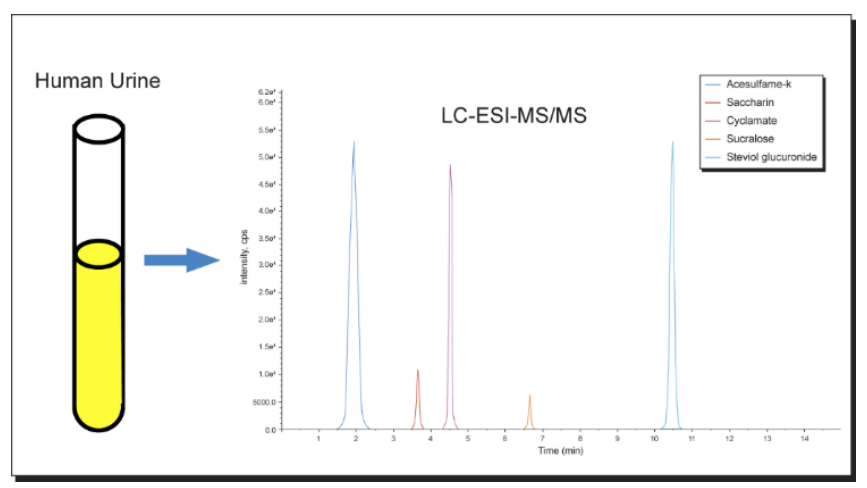

